\title{
Digging deeper: New gene order rearrangements and distinct patterns of codons usage in mitochondrial genomes among shrimps from the Axiidea, Gebiidea and Caridea (Crustacea: Decapoda)
}

\author{
Mun Hua Tan ${ }^{1,2}$, Han Ming Gan ${ }^{\text {Corresp., }}{ }^{1,2}$, Yin Peng Lee ${ }^{1,2}$, Gary C. B. Poore ${ }^{3}$, Christopher M Austin ${ }^{1,2,4}$ \\ ${ }^{1}$ School of Science, Monash University Malaysia, Bandar Sunway, Selangor, Malaysia \\ 2 Genomics Facility, Tropical Medicine and Biology Platform, Monash University Malaysia, Bandar Sunway, Selangor, Malaysia \\ 3 Museum of Victoria, Melbourne, Victoria, Australia \\ 4 School of Life and Environmental Sciences, Deakin University, Burwood, Australia \\ Corresponding Author: Han Ming Gan \\ Email address: gan.han.ming@monash.edu
}

Background. Whole mitochondrial DNA is being increasingly utilized for comparative genomic and phylogenetic studies at deep and shallow evolutionary levels for a range of taxonomic groups. Although mitogenome sequences are deposited at an increasing rate into public databases, their taxonomic representation is unequal across major taxonomic groups. In the case of decapod crustaceans, several infraorders, including Axiidea (ghost shrimps, sponge shrimps, mud lobsters) and Caridea (true shrimps), are still under-represented, limiting comprehensive phylogenetic studies that utilize mitogenomic information.

Methods. Sequence reads from partial genome scans were generated using the Illumina MiSeq platform and mitogenome sequences were assembled from these low coverage reads. In addition to examine phylogenetic relationships within the three infraorders, Axiidea, Gebiidea and Caridea, we also investigated the diversity and frequency of codon usage bias and mitogenome gene order rearrangements.

Results. We present new mitogenome sequences for five shrimp species from Australia that includes two ghost shrimps, Callianassa ceramica and Trypaea australiensis, along with three caridean shrimps, Macrobrachium bullatum, Alpheus lobidens and Caridina cf. nilotica. Strong differences in codon usage were discovered among the three infraorders and significant gene order rearrangements were observed. While the gene order rearrangements are congruent with the inferred phylogenetic relationships and consistent with taxonomic classification, they are unevenly distributed within and among the three infraorders.

Discussion. Our findings suggest potential for mitogenome rearrangements to be useful phylogenetic markers for decapod crustaceans and at the same time raise important questions concerning the drivers of mitogenome evolution in different decapod crustacean lineages. 
1 Digging deeper: New gene order rearrangements and distinct patterns of codons usage in 2 mitochondrial genomes among shrimps from the Axiidea, Gebiidea and

3 Caridea (Crustacea: Decapoda)

4

5 Mun Hua Tan ${ }^{1,2}$, Han Ming Gan ${ }^{1,2}$, Yin Peng Lee ${ }^{1,2}$, Gary C. B. Poore ${ }^{3}$ and Christopher M.

6 Austin $^{1,2,4}$

$9{ }^{1}$ School of Science, Monash University Malaysia, Jalan Lagoon Selatan, Bandar Sunway 47500, 10 Petaling Jaya, Selangor, Malaysia

$11{ }^{2}$ Genomics Facility, Tropical Medicine and Biology Platform, Monash University Malaysia,

12 Jalan Lagoon Selatan, Bandar Sunway 47500, Petaling Jaya, Selangor, Malaysia

${ }^{3}$ Museum Victoria, PO Box 666, Melbourne, Victoria, Australia

${ }^{4}$ School of Life and Environmental Sciences, Deakin University, Burwood, Victoria 3125 ,

Australia

\section{Corresponding author:}

Han Ming Gan ${ }^{1,2}$

Email address: gan.han.ming@monash.edu 
32 Abstract

33

Background. Whole mitochondrial DNA is being increasingly utilized for comparative genomic and phylogenetic studies at deep and shallow evolutionary levels for a range of taxonomic groups. Although mitogenome sequences are deposited at an increasing rate into public databases, their taxonomic representation is unequal across major taxonomic groups. In the case of decapod crustaceans, several infraorders, including Axiidea (ghost shrimps, sponge shrimps, mud lobsters) and Caridea (true shrimps), are still under-represented, limiting comprehensive phylogenetic studies that utilize mitogenomic information.

Methods. Sequence reads from partial genome scans were generated using the Illumina MiSeq platform and mitogenome sequences were assembled from these low coverage reads. In addition to examine phylogenetic relationships within the three infraorders, Axiidea, Gebiidea and Caridea, we also investigated the diversity and frequency of codon usage bias and mitogenome gene order rearrangements.

Results. We present new mitogenome sequences for five shrimp species from Australia that includes two ghost shrimps, Callianassa ceramica and Trypaea australiensis, along with three caridean shrimps, Macrobrachium bullatum, Alpheus lobidens and Caridina cf. nilotica. Strong differences in codon usage were discovered among the three infraorders and significant gene order rearrangements were observed. While the gene order rearrangements are congruent with the inferred phylogenetic relationships and consistent with taxonomic classification, they are unevenly distributed within and among the three infraorders.

Discussion. Our findings suggest potential for mitogenome rearrangements to be useful phylogenetic markers for decapod crustaceans and at the same time raise important questions concerning the drivers of mitogenome evolution in different decapod crustacean lineages.

\section{Introduction}

Sequencing of animal mitochondrial genomes has exploded in recent years. Over 40,000 animal mitogenomes are currently lodged on the NCBI database compared to fewer than 5,000 
63

64

65

66

67

68

69

sequences a decade ago. As mitogenomic data have accumulated it has become apparent that mitochondrial gene order is not as conserved as first thought, and that interesting and phylogenetically-useful patterns that invite further research are emerging (Boore 2006; Dowton et al. 2002; Gan et al. 2014a; Gissi et al. 2008; Lin et al. 2012; Poulsen et al. 2013; Tan et al. 2015).

In addition to gene order evolution, properties of mitogenome sequences that are of phylogenetic significance have emerged that are of interest to comparative mitogenomics such as gene loss and duplications, AT bias, strand asymmetry in nucleotide composition, length and structure of the control region, features of intergenic non-coding regions, codon usage, variation in gene length, variation in start and stop codons, gene diversity levels, mutation rates and signals of selection and secondary structures of ribosomal genes (Bauzà-Ribot et al. 2009; Gissi et al. 2008; Jia \& Higgs 2008; Li et al. 2015; Oliveira et al. 2008; Poulsen et al. 2013; Qian et al. 2011; Shoemaker et al. 2004). However, despite the rapidly accumulating mitogenomic resources, there are gaps in taxonomic representation and more data are required to fully evaluate the usefulness of mitogenome gene rearrangements as phylogenetic markers in specific groups (Mao et al. 2014; Tan et al. 2015) and for broadly-based comparative studies to detect patterns and investigate evolutionary hypotheses (Boore 2006; Castellana et al. 2011; Gissi et al. 2008; Jiang et al. 2007).

In general, the overall structure and function of animal mitochondrial genomes are remarkably stable. It is a circular, double-stranded DNA molecule of usually $15-20 \mathrm{~kb}$ in length, generally containing a consistent set of 37 genes made up of two ribosomal RNA genes (rRNA), 13 protein-coding genes (PCG) and 22 transfer RNA genes (tRNA) (Bernt et al. 2013; Castellana et al. 2011; Gissi et al. 2008). Intergenic regions are usually minimal, although all species contain at least one large AT-rich region associated with strand replication e.g. the control region. Mutations in the mitochondrial DNA can range from point mutations and infrequent insertions/deletions to gene order rearrangements. However, the type, scale and distribution of mutations can vary widely across various taxonomic levels (Gissi et al. 2008; Tan et al. 2015).

The most common mitogenome gene order rearrangements involve the translocation of single tRNA genes and occasionally with a change of transcriptional polarity or duplication. Less frequent is the repositioning of multiple tRNAs, duplication of the control region, or changes to the order and orientation of protein coding and rRNA genes. The paradox of mitogenome gene 
94 rearrangements is that the molecule can be highly conserved among phylogenetically-distant 95 species such as some insect and decapod crustacean species but can, in a restricted number of 96 taxonomic groups, also vary substantially among species in the same family or genus. Examples

97 of taxa with a concentration of reported mitogenome gene rearrangements include ticks (Fahrein 98 et al. 2007; Shao et al. 2005), hymenopterans (Dowton et al. 2003), gulper eels (Poulsen et al. 2013), salamanders (Chong \& Mueller 2013), tunicates (Gissi et al. 2004), and in several crustacean groups (Kilpert \& Podsiadlowski 2006; Kim et al. 2012; Miller et al. 2004; Stokkan et al. 2016; Tan et al. 2015).

Codon usage is another aspect of comparative mitogenomics that is attracting increasing

103

104

105

106

107

108

109

110

111

112

113

114

115

116

117

118

119

120

121

122

123

124 attention as research moves from describing patterns to understanding them within an evolutionary and molecular genetic context (Castellana et al. 2011; Gissi et al. 2008; Jiang et al. 2007). Amino acids can be encoded by two to six codons, but alternative codons for the same amino acid often do not occur at equal frequencies either between species for the same gene or between different genes in the one species. Patterns of differential codon usage have been attributable to selection, variable mutation rates, translational efficiency and random factors (genetic drift) (Castellana et al. 2011; Jia \& Higgs 2008; Prat et al. 2009; Whittle \& Extavour 2015). However, it has been rarely addressed among crustacean species (Cook et al. 2005; García-Machado et al. 1999; Rota-Stabelli et al. 2013).

As in other major animal groups, mitogenome sequences are becoming increasingly available for decapod crustacean species, contributing to the understanding of the evolution of this taxonomically challenging group due to its high diversity, deep lineages and highly flexible body plan (Shen et al. 2013; Tan et al. 2015). In addition, intriguing and taxonomically unevenly distributed gene order rearrangements are emerging, requiring further investigation and raising questions regarding the dynamics and drivers of mitogenome gene order evolution in several groups (Gan et al. 2015; Kilpert \& Podsiadlowski 2006; Miller et al. 2004). Two of the less wellrepresented decapod crustacean infraorders in mitochondrial databases are the shrimp infraorders Axiidea (ghost shrimps, sponge shrimps, mud lobsters) and Caridea (true shrimps) (Lin et al. 2012; Tan et al. 2015). Further, the phylogenetic relationships within and among these shrimp groups remain largely unresolved and disputed (Lin et al. 2012; Timm \& Bracken-Grissom 2015). A major limiting factor to the resolution of phylogenetic relationships within and among these shrimp lineages and the determination of the distribution and evolutionary significance of 
125 mitogenome gene order rearrangements is inadequate taxon sampling (Lin et al. 2012; Shen et al. 126 2013; Tan et al. 2015).

127 At the present time, the Axiidea, Gebiidea and Caridea are represented by only six, five 128 and 17 complete mitogenomes respectively on the NCBI public database. To support ongoing 129 phylogenetic and comparative mitogenomic studies, this paper reports five new mitogenome 130 sequences of shrimp species sampled from Australia. These include two mitogenomes from the

131 ghost shrimp, Callianassa ceramica Fulton \& Grant, 1906 and Trypaea australiensis Dana, 1852

132 (Callianassidae), and three from caridean shrimps Macrobrachium bullatum Fincham, 1987 133 (Paleamonidae), Alpheus lobidens De Haan, 1849 (Alpheidae) and Caridina cf. nilotica Roux, 1341833 (Atyidae), each of which represents highly diverse superfamilies, families and genera 135 within Caridea. This study compares the mitogenomic features of these five species together with 136 additional representatives of their infraorders and Gebiidea available from the NCBI database. In 137 addition to exploring evolutionary relationships within each infraorder, we uncover distinctive 138 signatures and patterns with respect to sequence composition, codon usage bias and gene 139 rearrangements that can possibly act as synapomorphies for specific shrimp taxonomic groups, 140 suggesting the potential of these features for phylogenetic inferences at different evolutionary 141 scales.

142

143

144

145

146

147

148

149

150

151

152

153

154

155

\section{Materials and Methods}

\section{Sample collection}

Two species belonging to the infraorder Axiidea (Callianassa ceramica, Trypaea australiensis) and three from Caridea (Macrobrachium bullatum, Alpheus lobidens, Caridina $\mathrm{cf}$. nilotica) were collected from different locations in Australia (Table 1). Callianassa ceramica is represented by two individuals: one from a vouchered specimen (Museum Victoria J40715; GenBank accession number KU350630.1); and the other a previously sequenced sample published incorrectly as T. australiensis (KM501040.1) (Gan et al. 2014b). The mitogenome sequence for this latter sample is now registered as $C$. ceramica under the accession number KU726823.1 and has a genetic similarity of $99.8 \%$ to the COI region of a vouchered C. ceramica specimen (Museum Victoria J70519) collected from the same general locality. 
156

157

158

159

160

161

162

163

164

165

166

167

168

169

170

171

172

173

174

175

176

177

178

179

180

181

182

183

184

185

186

To maintain continuity with the original NCBI accession number and species name, the original mitogenome sequence lodged on NCBI for T. australiensis was updated with the newlysequenced mitogenome from a vouchered T. australiensis specimen (Museum Victoria J40711; GenBank accession number: KM501040.2). The accession numbers for each species and associated collecting and identification-related information are detailed in Table 1 and Data S3, including voucher numbers for specimens lodged in in Museum Victoria, Melbourne (NMV) and the Museum and Art Gallery of the Northern Territory, Darwin (MAGNT).

Next-generation sequencing and mitogenome assembly

Purification of ethanol-preserved tissue and partial whole genome sequencing $(2 \times 75 \mathrm{bp}$ for T. australiensis and $2 \times 250 \mathrm{bp}$ for others) was performed on the Illumina MiSeq platform as previously described (Gan et al. 2014a), after which each mitogenome was assembled with IDBA_UD v.1.1.1 (Peng et al. 2012) and annotated using MITOS (Bernt et al. 2013). Circular mitogenome maps were drawn with BRIG v.0.9.5 (Alikhan et al. 2011). Summary statistics including gene boundaries and length, strand, nucleotide composition, intergenic nucleotides, and number of genes were compiled with MitoPhAST v.1.0 (Tan et al. 2015). Alignment of whole mitogenome sequences and calculation of pair-wise nucleotide identities were performed with SDT v.1.2 (Muhire et al. 2014).

\section{Gene order analysis}

Along with the five mitogenomes sequenced in this study, sequences from 28 other complete mitogenomes from the three infraorders were obtained from NCBI's RefSeq database (Table 2) for comparative analyses. Arrangements of genes for each of these 33 mitogenomes were compared with all other existing decapod mitogenomes in RefSeq to identify potential novel gene orders unreported by previous studies. Mitogenomes that exhibit gene orders differing from that of the pancrustacean ground pattern (Boore et al. 1998) were re-annotated with MITOS (Bernt et al. 2013) to confirm that differences observed are not due to misannotations. Any observed mis-annotations (e.g. missing genes, incorrect gene boundaries) were corrected before proceeding to further comparative and phylogenetic analyses. 
187

188

189

190

191

192

193

194

195

196

197

198

199

200

201

202

203

204

205

206

207

208

209

210

211

212

213

214

215

216

217

\section{Phylogenetic analysis}

Mitogenomes listed in Table 2 were subject to phylogenetic analysis to establish the evolutionary relationships of species within each of the infraorders to provide a framework for interpreting mitogenome gene rearrangements. MitoPhAST v.1.0 (Tan et al. 2015) was used to extract individual PCG amino acid sequences, and these protein sequences were then separately aligned with MAFFT v.7.222 (Katoh \& Standley 2013), followed by trimming with trimAl v.1.4 (Capella-Gutiérrez et al. 2009). For nucleotide level analyses, PCG nucleotide sequences were manually extracted and fed to TranslatorX v.1.1 (Abascal et al. 2010), which aligns nucleotide sequences guided by amino acid translations and then trimmed with Gblocks v.0.19b (Castresana 2000). On the other hand, rRNAwere aligned with MAFFT v.7.222 (mafft-linsi) (Katoh \& Standley 2013) and trimmed with trimAl v.1.4 (Capella-Gutiérrez et al. 2009). Finally, mitochondrial PCG and rRNA sequences were concatenated into super-alignments to make up the following datasets:
A. 13 PCG (aa) $[3,591$ characters $]$
B. 13 PCG (nt) $[9,642$ characters $]$
C. $13 \mathrm{PCG}(\mathrm{aa})+12 \mathrm{~S}$ rRNA $+16 \mathrm{~S}$ rRNA [5,694 characters $]$
D. 13 PCG (nt) + 12S rRNA + 16S rRNA [11,755 characters]

Maximum-likelihood (ML) tree inference with ultrafast bootstrap (UFBoot) branch supports (Minh et al. 2013) was performed using IQ-TREE v.1.5.0 (Nguyen et al. 2015), which also implements model selection to find the best-fit partitioning scheme. Super-alignments for all datasets were partitioned based on genes. An additional analysis for Dataset B that further partitions it according to $1^{\text {st }}, 2^{\text {nd }}$ and $3^{\text {rd }}$ codon positions was also performed. For Bayesian inference, the same super-alignments generated from all datasets were analyzed using Exabayes v.1.4.2 (Aberer et al. 2014). For each analysis, four independent runs were carried out concurrently for 5 million iterations each with $25 \%$ of initial samples discarded as burn-in. Convergence of chains was checked by ensuring the average standard deviation of split frequencies ( $a s d s f$ ) is below $0.5 \%$, considered to be good convergence according to the Exabayes 
218 user guide. Alignments, partitions and best-fit partitioning schemes for all datasets are available 219 as Data S1.

220

221

Codon usage analysis

222

223

Codon usage (in counts) was calculated using EMBOSS v.6.5.7 (Rice et al. 2000)

224

followed by minor adjustments based on the Invertebrate Mitochondrial Code (genetic code $=5$ ).

225

Comparisons among the three lineages of shrimps were made by applying the chi-square test to

226 the pooled codon usage counts for species from each infraorder. Relative Synonymous Codon

227 Usage (RSCU) values were calculated by taking the ratio of the number of times a codon appears to the expected frequency of the codon if all synonymous codons for a same amino acid are used equally (Sharp \& Li 1987). Patterns of variation among individuals in RSCU values were summarized using multidimensional scaling (MDS) based on Euclidean dissimilarities implemented in XLSTAT v.2015.4.01.20978 (Addinsoft 2010).

232

\section{Results}

\section{Mitogenome composition}

235

236

237

Mitogenomes for specimen J40715 of C. ceramica (16,899 bp, 130× cov), $T$. australiensis $(15,485 \mathrm{bp}, 86 \times \mathrm{cov})$, M. bullatum $(15,774 \mathrm{bp}, 27 \times \mathrm{cov})$, A. lobidens $(15,735 \mathrm{bp}$, $60 \times \mathrm{cov})$ and $C$. cf. nilotica $(15,497 \mathrm{bp}, 63 \times \mathrm{cov})$ were assembled into complete circular sequences, annotated (Fig. 1), and deposited in GenBank with accession numbers listed in Table 1. Four of the mitogenomes contain the typical 13 protein-coding genes, two ribosomal RNA genes, 22 transfer RNA genes and one long non-coding region while A. lobidens has an additional trn $Q$ flanked by the $N D 4 L$ and $\operatorname{trn} T$ genes (Fig. 1). Detailed composition of each mitogenome can be found in Table S1 while general information on \% AT and lengths for all mitogenomes included in this study are in Table S2. The mitogenomes are AT rich (58.9 69.7\%), with A. lobidens having the lowest AT content, matching closely to A. distinguendus (60.2\%), the only other species of Alpheus having a published mitogenome sequence. Gene lengths are typical but Callianassa and Trypaea have an elevated proportion of intergenic nucleotides, with some spacers in the order of $200 \mathrm{bp}$ in length. This is significantly larger than 
249 for other members of the Axiidea, but similar to spacers reported for the Gebiidea. Callianassa 250 ceramica (KU350630.1) has an unusually long control region of 2,036 bp, whereas for all the 251 other taxa it is less than $1,000 \mathrm{bp}$, including the closely-related T. australiensis (587 bp).

252 However, the control region for the conspecific C. ceramica (KU362925.1) is very similar $253(1,978 \mathrm{bp})$ and these two specimens are also very similar in terms of \% AT (69.7\% and 70.2\%). 254 A matrix of pair-wise identities of whole mitogenome sequence alignments can be found in Fig. 255 S1.

256

Manual inspection and MITOS annotation identified multiple erroneously annotated crustacean 258 mitogenomes in GenBank RefSeq database

259

260

261

262

263

264

265

266

267

268

269

270

271

272

273

274

275

276

277

278

279

The re-annotated species with gene orders divergent to that of the pancrustacean ground patterns obtained from GenBank's RefSeq database identified several that require revision. One was found to have a missing protein-coding gene and an extra trnS, and others inverted rRNA and tRNA coordinates and other annotation anomalies as detailed in Table 3. For our study, entries were edited based on MITOS annotations and the revised GenBank files for these entries are included as Data S2.

Whole mitogenomes are consistent with monophyly of infraorders Axiidea, Gebiidea and Caridea

A total of 33 mitogenome sequences from the three groups of interest were utilized (Axiidea: 8, Gebiidea: 5, Caridea: 20) to elucidate phylogenetic relationships, with an additional 12 Dendrobranchiata mitogenomes as outgroup (Table 2). Trees constructed from every dataset and analysis are available in Fig. S2. All trees place M. bullatum, A. lobidens and C. cf. nilotica as sister taxa to other species from their respective genera with relatively high nodal support (UFBoot $\geq 93 \%$, PP 1.00). These trees also consistently place $C$. ceramica as sister to $T$. australiensis (UFBoot 100\%, PP 1.00) within Axiidea.

The Bayesian-inferred phylogenetic tree in Fig. 2A, constructed based on amino acid sequences of 13 PCGs and nucleotide sequences of 2 rRNAs (Dataset C), shows a tree topology that is shared by most trees inferred in this study. Most nodes received maximal support from 
280

281

282

283

284

285

286

287

288

289

290

291

292

293

294

295

296

297

298

299

300

301

302

303

304

305

306

307

308

309

each analysis and dataset. The greatest levels of uncertainty in terms of phylogenetic placement are mostly relating to the relationships among closely-related taxa, such as in the Palaemon (6/10 trees), Rimicaris-Opaepele-Alvinocaris-Nautilocaris (2/10 trees), Upogebia-Austinogebia (1/10 trees), Corallianassa-Paraglypturus (1/10 trees) and Macrobrachium (1/10 trees) clades. The only deeper clade with low support is the placement of Atyidae as the sister clade of Alvinocarididae within Caridea (UFBoot $\geq 90$, PP 1.00). Within Axiidea, maximal support is observed for almost all nodes. The most basal split in this infraorder separates Strahlaxiidae (Neaxius glyptocerus) from Callianassidae. Within Callianassidae, the three major lineages correspond to accepted subfamilies, two represented by one species each and Callianassinae by four species. In as far as it goes, the phylogenetic placements of mitogenome sequences in Axiidea are congruent with the current classification at the family, subfamily and generic levels (Felder \& Robles 2009) (Fig. 2A). These analyses of just four upogebiid species indicate that Upogebia may be paraphyletic with respect to Austinogebia. Since these two genera are nominally represented by over 120 and eight species respectively, any comment on their status is premature at this stage. The degree of divergence between the species of Rimicaris and Opaepele is small relative to the degree of divergence between congeneric species within Macrobrachium, Alpheus, Caridina and Alvinocaris.

Deviation from the pancrustacean ground pattern is prevalent in the currently sequenced members of the Axiidea and Gebiidea

Most mitogenomes from caridean species have the pancrustacean ground pattern (pattern $G r$, Fig. 2B). Those that do differ show only minor rearrangements involving the short tRNA genes (patterns $P a, A p 1$ and $A p 2$ ). In contrast, the mitogenomes of species within Axiidea and Gebiidea exhibit relatively substantial differences in gene order (patterns $U p, A x 1$ and $A x 2$ ) entailing rearrangements of protein-coding genes, rRNAs and a number of tRNAs. An example is pattern $A x 2$ shown in Fig. 2B, which includes the inversion of the ND1, $\operatorname{lr} R N A$, $\operatorname{rrR} A A$ and $\operatorname{trn} I$ genes as a block, in addition to the inversion and translocation of $\operatorname{trn} D$ from between $\operatorname{trn} Q$ and $\operatorname{trn} M$ to a position between $\operatorname{trn} S 2$ and the putative control region, as well as new placements for $\operatorname{trn} L$ and $\operatorname{trn} V$ also evident in pattern $A x 1$. 
All gene order novelties relative to the pancrustacean ground pattern are consistent with

311 the relationships depicted by the molecular phylogeny, and in several cases define taxonomic

312 groups at different levels. In Caridea, pattern $\mathrm{Pa}$ is common to the three Palaemon species and

313 pattern Apl defines the two Alpheus species. Similarly, within Gebiidea, while Thalassina

314 kelanang (family Thalassinidae) has the ground pancrustacean pattern, the other four species are

315 all members of the family Upogebiidae and are united by novel rearrangements involving several

316 tRNA translocations (pattern $U p$, Fig 2B). Pattern $A x 1$, involving the rearrangements of COIII

317 and several tRNAs, is shared among species of Axiidea. The elements of pattern Ax2 that differ

318 from pattern Axl support the node joining Callianassa and Trypaea.

319

320

Evidence of significant codon usage bias in mitochondrial genomes at the infraorder level

321

322

323

324

325

326

327

328

329

330

331

332

333

334

335

336

337

Figure 3 shows there is strong $\mathrm{A}+\mathrm{T}$ bias in codon usage across the 33 shrimp mitogenomes. Relative synonymous codon usage frequencies (RSCU) demonstrate distinct preference for codons with $\mathrm{A}$ or $\mathrm{T}$ in the third codon position compared to other synonymous codons. Counts of codons used and RSCU values can be found in Table S3. Among the 62 available codons, the four most used codons in all three infraorders are TTT (Phe), TTA (Leu), ATT (Ile) and ATA (Met), all made up of solely A and T nucleotides. Even so, this preference for $\mathrm{A}+\mathrm{T}$ codons is stronger in Axiidea and Gebiidea mitogenomes and less so in Caridea, most obvious for amino acids Asp (D), His (H), Asn (N) and Tyr (Y). Statistical comparisons show that, for each amino acid, there are significant differences among the three infraorders in the proportions of the codons being used ( $p$-values in Fig. 3). A separate comparison for species with pattern $A x 1$ and $A \times 2$ within the infraorder Axiidea and also with those with the ground pattern (Gr) do not reveal any substantial difference in their codon usage bias (Fig. S3). The MDS plot shows that, for the most part, members of each infraorder cluster together and are largely distinct from the samples from the other infraorders (Fig. 4). A sample of the Gebiidea, T. kelanang, is a maverick, being placed well inside the Caridea cluster and remote from the other members of its infraorder. It also has a very low AT content for this group, being more similar to caridean shrimps. In this context, it is noteworthy that the species is placed as the most basal member of the Gebiidea and is also the only member of the infraorder that has the primitive pancrustacean 
340

341

342

343

344

345

346

347

348

349

350

351

352

353

354

355

356

357

358

359

360

361

362

363

364

365

366

367

368

369

370

gene order, which it shares with all other of the members of the Caridea with the exception of some species with minor derived rearrangements (Fig. 2B).

\section{Discussion}

The five new decapod mitogenomes presented in this study considerably expand the number of samples of Axiidea and Caridea currently available for mitogenome-based phylogenetics and comparative mitogenomic studies. Members of the infraorder Gebiidea were also included in this analysis due to its taxonomic history of having been placed with Axiidea in the infraorder Thalassinidea, prior to obtaining recent recognition as its own separate infraorder (Ahyong \& O’Meally 2004; Crandall et al. 2000; Robles et al. 2009; Timm \& Bracken-Grissom 2015). The mitogenomic features of these taxa are generally consistent with those for the Decapoda and for the three infraorders (Kim et al. 2013; Lin et al. 2012; Miller et al. 2005) (Table S1). In addition, the high AT content (58.9-73.6\%) observed in all of the mitogenomes utilized in this study is typical for the Crustacea and the Arthropoda (Cameron 2014; Cook et al. 2005; Lin et al. 2012; Shen et al. 2015).

It has been suggested that evolutionary rate and the frequency of rearrangements are independent (Gissi et al. 2008) and this is consistent with results depicted in Fig. 2, which indicate no obvious correlations between the size and distribution of rearrangements and branch lengths (substitution rate) within and between groups. Despite this general observation some studies have noted an association between higher substitution rates and the occurrence of mitogenome rearrangements involving a transfer of genes between strands (e.g. Stokkan et al. (2016). Although it is expected that codon usage varies between major groups of organisms and among animal phyla (Castellana et al. 2011; Gissi et al. 2008; Prat et al. 2009), finding substantial codon usage differences at the infraorder level is somewhat unusual. It is becoming more apparent now that there are divergent patterns in AT content among orders in insects and among the major taxonomic groups in the Malacostraca (see Table 1 in Sun et al. (2009) and Table 1 in Shen et al. (2015)). Studies examining patterns of codon usage in mitogenomes have failed to observe differences at finer taxonomic scales within insects and crustaceans (Cook et al. 2005; Shen et al. 2015; Sun et al. 2009).

Elevated mutational pressure is thought to be a major driver of non-random mitochondrial synonymous variation. However, selection of optimal codons for translational 
371 efficiency and genetic drift is also thought to play a role (Castellana et al. 2011; Jia \& Higgs

372 2008; Prat et al. 2009). It is tempting to speculate that the distinctive pattern of codon usage in

373 the Axiidea, and the frequency and extent of mitogenome gene order rearrangements may be

374 correlated with the acquisition of specialized adaptations by members of this infraorder to largely

375 burrowing lifestyles (Lin et al. 2012; Sakai 2011) compared to the members of the Caridea,

376 which are mostly free living (Bracken et al. 2009).

377 The phylogenetic analyses using whole mitogenomes support the monophyly of each of

378 the three infraorders, Axiidea, Gebiidea and Caridea, with inclusion of more comprehensive

379 taxon sampling than previous studies (Lin et al. 2012; Shen et al. 2013; Shen et al. 2015; Tan et

380 al. 2015). Further, the members of Axiidea have a common gene rearrangement that is a potential

381 synapomorphy of the infraorder, and therefore also supports the monophyly of this group. A

382 notable exception to these results is the analysis of Shen et al. (2015), which supported a non-

383 monophyletic Gebiidea, by placing T. kelanang inside a lineage comprising Acheleta,

384 Polychelida and Caridea. Other studies using a combination of mitochondrial and nuclear gene

385 fragments (Bracken et al. 2009; Robles et al. 2009) also support the monophyly of these groups,

386 but their relationships with each other and other decapod infraorders have yet to be resolved (Tan

387 et al. 2015). A caveat of our findings and those of other studies is that monophyly cannot be fully

388 tested without comprehensive taxonomic and gene sampling and the inclusion of species from all

389 decapod infraorders (Timm \& Bracken-Grissom 2015).

The contribution of mitogenomic data for more species will be particularly important for exploring and testing evolutionary relationships within Axiidea, given its lack of broad taxonomic representation on the current evolutionary tree. Two of the mitogenomes contributed in this study (C. ceramica, T. australiensis) belong to the family Callianassidae, a diverse group of axiidean shrimps adapted to digging in soft marine sediments. Over 100 species placed in 22 genera and divided between several subfamilies are recognized from this family (Sakai 2011). However, relationships among the major groups and the definition of subfamily and generic level boundaries are contentious within the Callianassidae (Poore et al. 2014; Sakai 2011). It is noteworthy that for the Axiidea, the tree-based relationships and the mitogenome rearrangements samples included (Fig. 2), and that the phylogenetic tree and the $A x l$ rearrangement pattern 
402

403

404

405

406

407

408

409

410

411

412

413

414

415

416

417

418

419

420

421

422

423

424

425

426

427

428

429

430

431

432

The potential for mitochondrial rearrangement to act as "super" characters for phylogenetic estimation for the arthropod has been recognised by a number of authors (Boore et al. 1998; Dowton \& Austin 1999; Dowton et al. 2002). This study further supports this position but also notes that the distribution of rearrangements is uneven across the tree generated in this study and the larger analysis by Tan et al. (2015). Thus, while novel gene order attributes act as useful phylogenetic characters for the Axiidea and Gebiidea, their usefulness appear to be limited for the Caridea, even though the age of the lineages overlap. Similarly, for other major crustaceans groups, lobsters (Astacidea and Achelata), crabs (Brachyura) and penaeid shrimps (Dendrobranchiata), rearrangements are largely absent or minor (Shen et al. 2015; Tan et al. 2015), but freshwater crayfish (Astacidea) and anomuran crabs (Anomura) are phylogenetic "hotspots" for mitogenome gene order evolution in both the number and scale of rearrangements. As pointed out by Mao et al. (2014), far greater sampling is required to adequately test the phylogenetic utility of observed mitogenome gene rearrangements and identification of suitable models for investigating the evolutionary and molecular drivers that shape the organization and architecture of animal mitogenomes.

In this regard, rapid and efficient methods for mitogenome sequencing using nextgeneration sequencing (NGS) platforms will accelerate this task (Gan et al. 2014a; Timmermans et al. 2016). Unlike more classical methods utilizing long-range PCR to amplify the mitogenome into a smaller number of fragments with universal primers, followed by Sanger sequencing (Lin et al. 2012; Miller et al. 2004; Shen et al. 2013), the primer-free and shotgun nature of NGS will likely increase the discovery of mitogenome rearrangements as it makes no assumptions about the pre-existing gene order of the species under study. In fact, the availability of a reference whole mitogenome will improve primer design and consequently the success rate of complete mitogenome recovery from members of the same genus (or family) using long-range PCR. It is envisaged with the advent of third generation sequencing technology such as PacBio (Rhoads \& $\mathrm{Au} 2015$ ) and Nanopore (Branton et al. 2008) sequencing, problematic and repetitive regions commonly associated with the control region can be readily resolved and confirmed.

Lastly, while preparing the dataset for analysis, we identified several misannotated mitogenomes on NCBI (Table 3) although these misannotations were absent in their related publications i.e. the correct gene coordinates and orientations were reported by the authors of in their respective publications. We postulate that these discrepancies may have arisen due to errors 
433 during the submission of these mitogenomes to public databases ${ }^{1}$. It is also possible, though less

434 likely, that the mitogenomes may have been erroneously edited when they were reviewed by

435 NCBI staff. Hence, this highlights that although there is tremendous gain from having a growing

436 number of mitogenome submissions to public databases as molecular resources, the accuracy of

437 annotations should not be assumed and it is prudent to re-evaluate species with any form of gene

438 order rearrangements or related anomalies before inclusion in datasets for comparative analyses.

439

440 Acknowledgements

441 MHT and HMG would like to acknowledge the Monash University Malaysia High Performance

442 Computing infrastructure for the provision of computational resources. We are also grateful to C.

443 Tudge for collecting and providing the Trypaea australiensis sample and Joanne Taylor,

444 Museum Victoria, for making it available. The authors are also grateful for helpful comments of

445 the anonymous reviews that significantly improved the manuscript.

\section{References}

Abascal F, Zardoya R, and Telford MJ. 2010. TranslatorX: multiple alignment of nucleotide sequences guided by amino acid translations. Nucleic Acids Research 38:W7-W13. 10.1093/nar/gkq291

Aberer AJ, Kobert K, and Stamatakis A. 2014. ExaBayes: Massively Parallel Bayesian Tree Inference for the Whole-Genome Era. Molecular biology and evolution 31:2553-2556. $10.1093 / \mathrm{molbev} / \mathrm{msu} 236$

Addinsoft. 2010. XLSTAT 2015, Data analysis and statistics software for Microsoft Excel. Addinsoft Paris, France.

Ahyong ST, and O'Meally D. 2004. Phylogeny of the Decapoda Reptantia: resolution using three molecular loci and morphology. The Raffles Bulletin of Zoology 52:673-693.

Alikhan N-F, Petty NK, Ben Zakour NL, and Beatson SA. 2011. BLAST Ring Image Generator (BRIG): simple prokaryote genome comparisons. BMC Genomics 12:1-10. 10.1186/1471-2164-12-402

Bauzà-Ribot MM, Jaume D, Juan C, and Pons J. 2009. The complete mitochondrial genome of the subterranean crustacean Metacrangonyx longipes (Amphipoda): A unique gene order and extremely short control region. Mitochondrial DNA 20:88-99. 10.1080/19401730902964417

Bernt M, Donath A, Jühling F, Externbrink F, Florentz C, Fritzsch G, Pütz J, Middendorf M, and Stadler PF. 2013. MITOS: Improved de novo metazoan mitochondrial genome annotation. Molecular Phylogenetics and Evolution 69:313-319. http://dx.doi.org/10.1016/j.ympev.2012.08.023

Boore JL. 2006. The use of genome-level characters for phylogenetic reconstruction. Trends in Ecology \& Evolution 21:439-446. http://dx.doi.org/10.1016/j.tree.2006.05.009

\footnotetext{
${ }^{1}$ At the time of writing, notifications have been submitted to NCBI to alert them of inconsistencies in the four mitogenomes reported in this study.
} 
468

469

470

471

472

473

474

475

476

477

478

479

480

481

482

483

484

485

486

487

488

489

490

491

492

493

494

495

496

497

498

499

500

501

502

503

504

505

506

507

508

509

510

511

512

513

514

Boore JL, Lavrov DV, and Brown WM. 1998. Gene translocation links insects and crustaceans. Nature 392:667-668.

Bracken HD, De Grave S, and Felder DL. 2009. Phylogeny of the infraorder Caridea based on mitochondrial and nuclear genes (Crustacea: Decapoda). Decapod crustacean phylogenetics:281-305.

Branton D, Deamer DW, Marziali A, Bayley H, Benner SA, Butler T, Di Ventra M, Garaj S, Hibbs A, Huang $X$, Jovanovich SB, Krstic PS, Lindsay S, Ling XS, Mastrangelo CH, Meller A, Oliver JS, Pershin YV, Ramsey JM, Riehn R, Soni GV, Tabard-Cossa V, Wanunu M, Wiggin M, and Schloss JA. 2008. The potential and challenges of nanopore sequencing. Nat Biotech 26:1146-1153.

Cameron SL. 2014. Insect Mitochondrial Genomics: Implications for Evolution and Phylogeny. Annual Review of Entomology 59:95-117. doi:10.1146/annurev-ento-011613-162007

Capella-Gutiérrez S, Silla-Martínez JM, and Gabaldón T. 2009. trimAl: a tool for automated alignment trimming in large-scale phylogenetic analyses. Bioinformatics 25:1972-1973. 10.1093/bioinformatics/btp348

Castellana S, Vicario S, and Saccone C. 2011. Evolutionary Patterns of the Mitochondrial Genome in Metazoa: Exploring the Role of Mutation and Selection in Mitochondrial Protein-Coding Genes. Genome Biology and Evolution 3:1067-1079. 10.1093/gbe/evr040

Chong RA, and Mueller RL. 2013. Evolution Along the Mutation Gradient in the Dynamic Mitochondrial Genome of Salamanders. Genome Biology and Evolution 5:1652-1660. 10.1093/gbe/evt119

Cook CE, Yue $Q$, and Akam M. 2005. Mitochondrial genomes suggest that hexapods and crustaceans are mutually paraphyletic. Proceedings of the Royal Society of London B: Biological Sciences 272:1295-1304. 10.1098/rspb.2004.3042

Crandal KA, Harris DJ, and Fetzner JW. 2000. The monophyletic origin of freshwater crayfish estimated from nuclear and mitochondrial DNA sequences. Proceedings of the Royal Society of London B: Biological Sciences 267:1679-1686. 10.1098/rspb.2000.1195

Darriba D, Taboada GL, Doallo R, and Posada D. 2012. jModelTest 2: more models, new heuristics and parallel computing. Nat Meth 9:772-772. http://www.nature.com/nmeth/journal/v9/n8/abs/nmeth.2109.html\#supplementaryinformation

Dowton M, and Austin AD. 1999. Evolutionary dynamics of a mitochondrial rearrangement "hot spot" in the Hymenoptera. Molecular biology and evolution 16:298-309.

Dowton M, Castro LR, and Austin AD. 2002. Mitochondrial gene rearrangements as phylogenetic characters in the invertebrates: the examination of genome 'morphology'. Invertebrate Systematics 16:345-356. http://dx.doi.org/10.1071/IS02003

Dowton M, Castro RL, Campbell LS, Bargon DS, and Austin DA. 2003. Frequent Mitochondrial Gene Rearrangements at the Hymenopteran nad3-nad5 Junction. Journal of Molecular Evolution 56:517-526. 10.1007/s00239-002-2420-3

Fahrein K, Talarico G, Braband A, and Podsiadlowski L. 2007. The complete mitochondrial genome of Pseudocellus pearsei (Chelicerata: Ricinulei) and a comparison of mitochondrial gene rearrangements in Arachnida. BMC Genomics 8:1-14. 10.1186/1471-2164-8-386

Felder DL, and Robles R. 2009. Molecular phylogeny of the family Callianassidae based on preliminary analyses of two mitochondrial genes. Decapod crustacean phylogenetics Crustacean issues 18:327-342.

Gan HM, Schultz MB, and Austin CM. 2014a. Integrated shotgun sequencing and bioinformatics pipeline allows ultra-fast mitogenome recovery and confirms substantial gene rearrangements in Australian freshwater crayfishes. BMC Evol Biol 14:19. 10.1186/1471-2148-14-19

1471-2148-14-19 [pii] 
515

516

517

518

519

520

521

522

523

524

525

526

527

528

529

530

531

532

533

534

535

536

537

538

539

540

541

542

543

544

545

546

547

548

549

550

551

552

553

554

555

556

557

558

559

560

Gan HY, Gan HM, Lee YP, and Austin CM. 2014b. The complete mitochondrial genome of the bass yabby Trypaea australiensis Dana 1852, (Crustacea; Decapoda; Callianassidae) - a new gene order for the Decapoda. Mitochondrial DNA:1-2. 10.3109/19401736.2014.989516

Gan HY, Gan HM, Tan MH, Lee YP, and Austin CM. 2015. The complete mitogenome of the hermit crab Clibanarius infraspinatus (Hilgendorf, 1869), (Crustacea; Decapoda; Diogenidae) - a new gene order for the Decapoda. Mitochondrial DNA:1-2. 10.3109/19401736.2014.1003862

García-Machado E, Pempera M, Dennebouy N, Oliva-Suarez M, Mounolou J-C, and Monnerot M. 1999. Mitochondrial Genes Collectively Suggest the Paraphyly of Crustacea with Respect to Insecta. Journal of Molecular Evolution 49:142-149. 10.1007/pl00006527

Gissi C, lannelli F, and Pesole G. 2004. Complete mtDNA of Ciona intestinalis Reveals Extensive Gene Rearrangement and the Presence of an atp8 and an Extra trnM Gene in Ascidians. Journal of Molecular Evolution 58:376-389. 10.1007/s00239-003-2559-6

Gissi C, lannelli F, and Pesole G. 2008. Evolution of the mitochondrial genome of Metazoa as exemplified by comparison of congeneric species. Heredity 101:301-320. http://www.nature.com/hdy/journal/v101/n4/suppinfo/hdy200862s1.html

Jia W, and Higgs PG. 2008. Codon Usage in Mitochondrial Genomes: Distinguishing Context-Dependent Mutation from Translational Selection. Molecular biology and evolution 25:339-351. 10.1093/molbev/msm259

Jiang ZJ, Castoe TA, Austin CC, Burbrink FT, Herron MD, McGuire JA, Parkinson CL, and Pollock DD. 2007. Comparative mitochondrial genomics of snakes: extraordinary substitution rate dynamics and functionality of the duplicate control region. BMC Evolutionary Biology 7:1-14. 10.1186/14712148-7-123

Katoh K, and Standley DM. 2013. MAFFT multiple sequence alignment software version 7: improvements in performance and usability. Molecular biology and evolution 30:772-780.

Kilpert F, and Podsiadlowski L. 2006. The complete mitochondrial genome of the common sea slater, Ligia oceanica (Crustacea, Isopoda) bears a novel gene order and unusual control region features. BMC Genomics 7:1-18. 10.1186/1471-2164-7-241

Kim S, Ahn D-H, Park J-K, Kim S-J, Choi H-G, and Min G-S. 2013. The complete mitochondrial genome of the Japanese ghost shrimp Nihonotrypaea japonica (Crustacea, Decapoda, Axiidea). Mitochondrial DNA 24:243-245. 10.3109/19401736.2012.752480

Kim S, Park M-H, Jung J-H, Ahn D-H, Sultana T, Kim S, Park J-K, Choi H-G, and Min G-S. 2012. The mitochondrial genomes of Cambaroides similis and Procambarus clarkii (Decapoda: Astacidea: Cambaridae): the phylogenetic implications for Reptantia. Zoologica Scripta 41:281-292. 10.1111/j.1463-6409.2012.00534.x

Li X, Huang Y, and Lei F. 2015. Comparative mitochondrial genomics and phylogenetic relationships of the Crossoptilon species (Phasianidae, Galliformes). BMC Genomics 16:1-12. 10.1186/s12864015-1234-9

Lin F-J, Liu Y, Sha Z, Tsang L, Chu K, Chan T-Y, Liu R, and Cui Z. 2012. Evolution and phylogeny of the mud shrimps (Crustacea: Decapoda) revealed from complete mitochondrial genomes. BMC Genomics 13:631.

Mao M, Gibson T, and Dowton M. 2014. Evolutionary Dynamics of the Mitochondrial Genome in the Evaniomorpha (Hymenoptera)-A Group with an Intermediate Rate of Gene Rearrangement. Genome Biology and Evolution 6:1862-1874. 10.1093/gbe/evu145

Miller AD, Murphy NP, Burridge CP, and Austin CM. 2005. Complete Mitochondrial DNA Sequences of the Decapod Crustaceans Pseudocarcinus gigas (Menippidae) and Macrobrachium rosenbergii (Palaemonidae). Marine Biotechnology 7:339-349. 10.1007/s10126-004-4077-8 
561

562

563

564

565

566

567

568

569

570

571

572

573

574

575

576

577

578

579

580

581

582

583

584

585

586

587

588

589

590

591

592

593

594

595

596

597

598

599

600

601

602

603

604

605

606

607

Miller AD, Nguyen TTT, Burridge CP, and Austin CM. 2004. Complete mitochondrial DNA sequence of the Australian freshwater crayfish, Cherax destructor (Crustacea: Decapoda: Parastacidae): a novel gene order revealed. Gene 331:65-72. http://dx.doi.org/10.1016/j.gene.2004.01.022

Murphy NP, and Austin CM. 2004. Multiple origins of the endemic Australian Macrobrachium (Decapoda : Palaemonidae) based on 16S rRNA mitochondrial sequences. Australian Journal of Zoology 52:549-559. http://dx.doi.org/10.1071/ZO03062

Oliveira DCSG, Raychoudhury R, Lavrov DV, and Werren JH. 2008. Rapidly Evolving Mitochondrial Genome and Directional Selection in Mitochondrial Genes in the Parasitic Wasp Nasonia (Hymenoptera: Pteromalidae). Molecular biology and evolution 25:2167-2180. $10.1093 / \mathrm{molbev} / \mathrm{msn} 159$

Page TJ, von Rintelen K, and Hughes JM. 2007. An island in the stream: Australia's place in the cosmopolitan world of Indo-West Pacific freshwater shrimp (Decapoda: Atyidae: Caridina). Molecular Phylogenetics and Evolution 43:645-659. http://dx.doi.org/10.1016/j.ympev.2006.08.007

Peng Y, Leung HCM, Yiu SM, and Chin FYL. 2012. IDBA-UD: a de novo assembler for single-cell and metagenomic sequencing data with highly uneven depth. Bioinformatics 28:1420-1428. 10.1093/bioinformatics/bts174

Poore GC. 1994. A phylogeny of the families of Thalassinidea (Crustacea: Decapoda) with keys to families and genera. Memoirs of the Museum of Victoria 54:79-120.

Poore GCB, Ahyong ST, Bracken-Grissom HD, Chan T-Y, Chu KH, Crandall KA, Dworschak PC, Felder DL, Feldmann RM, Hyžný M, Karasawa H, Lemaitre R, Komai T, Li X, Mantelatto FL, Martin JW, NgocHo N, Robles R, Schweitzer CE, Tamaki A, Tsang LM, and Tudge CC. 2014. On stabilising the names of the infraorders of thalassinidean shrimps, Axiidea de Saint Laurent, 1979 and Gebiidea de Saint Laurent, 1979 (Decapoda). Crustaceana 87:1258-1272. doi:http://dx.doi.org/10.1163/15685403-00003354

Poulsen JY, Byrkjedal I, Willassen E, Rees D, Takeshima H, Satoh TP, Shinohara G, Nishida M, and Miya M. 2013. Mitogenomic sequences and evidence from unique gene rearrangements corroborate evolutionary relationships of myctophiformes (Neoteleostei). BMC Evolutionary Biology 13:1-22. 10.1186/1471-2148-13-111

Prat $\mathrm{Y}$, Fromer M, Linial N, and Linial M. 2009. Codon usage is associated with the evolutionary age of genes in metazoan genomes. BMC Evolutionary Biology 9:1-12. 10.1186/1471-2148-9-285

Qian G, Zhao Q, Wang AN, Zhu LIN, Zhou K, and Sun H. 2011. Two new decapod (Crustacea, Malacostraca) complete mitochondrial genomes: bearings on the phylogenetic relationships within the Decapoda. Zoological Journal of the Linnean Society 162:471-481. 10.1111/j.10963642.2010.00686.x

Rhoads A, and Au KF. 2015. PacBio Sequencing and Its Applications. Genomics, Proteomics \& Bioinformatics 13:278-289. http://dx.doi.org/10.1016/j.gpb.2015.08.002

Rice P, Longden I, and Bleasby A. 2000. EMBOSS: The European Molecular Biology Open Software Suite. Trends in Genetics 16:276-277. 10.1016/s0168-9525(00)02024-2

Robles R, Tudge CC, Dworschak PC, Poore GC, and Felder D. 2009. Molecular phylogeny of the Thalassinidea based on nuclear and mitochondrial genes. Decapod crustacean phylogenetics:309-326.

Rota-Stabelli O, Lartillot N, Philippe H, and Pisani D. 2013. Serine Codon-Usage Bias in Deep Phylogenomics: Pancrustacean Relationships as a Case Study. Systematic Biology 62:121-133. 10.1093 /sysbio/sys077

Sakai K. 2011. Axioidea of the world and a reconsideration of the Callianassoidea (Decapoda, Thalassinidea, Callianassida): Brill. 
608

609

610

611

612

613

614

615

616

617

618

619

620

621

622

623

624

625

626

627

628

629

630

631

632

633

634

635

636

637

638

639

640

641

642

643

644

645

646

647

648

649

650

651

652

653

654

Shao R, Barker SC, Mitani H, Aoki Y, and Fukunaga M. 2005. Evolution of Duplicate Control Regions in the Mitochondrial Genomes of Metazoa: A Case Study with Australasian Ixodes Ticks. Molecular biology and evolution 22:620-629. 10.1093/molbev/msi047

Sharp PM, and Li W-H. 1987. The codon adaptation index-a measure of directional synonymous codon usage bias, and its potential applications. Nucleic Acids Research 15:1281-1295. 10.1093/nar/15.3.1281

Shen H, Braband A, and Scholtz G. 2013. Mitogenomic analysis of decapod crustacean phylogeny corroborates traditional views on their relationships. Molecular Phylogenetics and Evolution 66:776-789. http://dx.doi.org/10.1016/i.ympev.2012.11.002

Shen X, Tian M, Yan B, and Chu K. 2015. Phylomitogenomics of Malacostraca (Arthropoda: Crustacea). Acta Oceanologica Sinica 34:84-92. 10.1007/s13131-015-0583-1

Shoemaker DD, Dyer KA, Ahrens M, McAbee K, and Jaenike J. 2004. Decreased diversity but increased substitution rate in host mtDNA as a consequence of Wolbachia endosymbiont infection. Genetics 168:2049-2058.

Stamatakis A. 2014. RAxML version 8: a tool for phylogenetic analysis and post-analysis of large phylogenies. Bioinformatics. 10.1093/bioinformatics/btu033

Sun Z, Wan D-G, Murphy RW, Ma L, Zhang X-S, and Huang D-W. 2009. Comparison of base composition and codon usage in insect mitochondrial genomes. Genes \& Genomics 31:65-71. 10.1007/bf03191139

Tan MH, Gan HM, Schultz MB, and Austin CM. 2015. MitoPhAST, a new automated mitogenomic phylogeny tool in the post-genomic era with a case study of 89 decapod mitogenomes including eight new freshwater crayfish mitogenomes. Molecular Phylogenetics and Evolution 85:180-188. http://dx.doi.org/10.1016/j.ympev.2015.02.009

Timm L, and Bracken-Grissom HD. 2015. The forest for the trees: evaluating molecular phylogenies with an emphasis on higher-level Decapoda. JOURNAL OF CRUSTACEAN BIOLOGY 35:577-592. doi:http://dx.doi.org/10.1163/1937240X-00002371

Timmermans MJTN, Viberg C, Martin G, Hopkins K, and Vogler AP. 2016. Rapid assembly of taxonomically validated mitochondrial genomes from historical insect collections. Biological Journal of the Linnean Society 117:83-95. 10.1111/bij.12552

Whittle CA, and Extavour CG. 2015. Codon and Amino Acid Usage Are Shaped by Selection Across Divergent Model Organisms of the Pancrustacea. G3: Genes/Genomes/Genetics 5:2307-2321. 10.1534/g3.115.021402

Abascal F, Zardoya R, and Telford MJ. 2010. TranslatorX: multiple alignment of nucleotide sequences guided by amino acid translations. Nucleic Acids Research 38:W7-W13. 10.1093/nar/gkq291

Aberer AJ, Kobert K, and Stamatakis A. 2014. ExaBayes: Massively Parallel Bayesian Tree Inference for the Whole-Genome Era. Molecular biology and evolution 31:2553-2556. 10.1093/molbev/msu236

Addinsoft. 2010. XLSTAT 2015, Data analysis and statistics software for Microsoft Excel. Addinsoft Paris, France.

Ahyong ST, and O'Meally D. 2004. Phylogeny of the Decapoda Reptantia: resolution using three molecular loci and morphology. The Raffles Bulletin of Zoology 52:673-693.

Alikhan N-F, Petty NK, Ben Zakour NL, and Beatson SA. 2011. BLAST Ring Image Generator (BRIG): simple prokaryote genome comparisons. BMC Genomics 12:1-10. 10.1186/1471-2164-12-402

Bauzà-Ribot MM, Jaume D, Juan C, and Pons J. 2009. The complete mitochondrial genome of the subterranean crustacean Metacrangonyx longipes (Amphipoda): A unique gene order and extremely short control region. Mitochondrial DNA 20:88-99. 10.1080/19401730902964417 
655

656

657

658

659

660

661

662

663

664

665

666

667

668

669

670

671

672

673

674

675

676

677

678

679

680

681

682

683

684

685

686

687

688

689

690

691

692

693

694

695

696

697

698

699

700

Bernt M, Donath A, Jühling F, Externbrink F, Florentz C, Fritzsch G, Pütz J, Middendorf M, and Stadler PF. 2013. MITOS: Improved de novo metazoan mitochondrial genome annotation. Molecular Phylogenetics and Evolution 69:313-319. http://dx.doi.org/10.1016/j.ympev.2012.08.023

Boore JL. 2006. The use of genome-level characters for phylogenetic reconstruction. Trends in Ecology \& Evolution 21:439-446. http://dx.doi.org/10.1016/j.tree.2006.05.009

Boore JL, Lavrov DV, and Brown WM. 1998. Gene translocation links insects and crustaceans. Nature 392:667-668.

Bracken HD, De Grave S, and Felder DL. 2009. Phylogeny of the infraorder Caridea based on mitochondrial and nuclear genes (Crustacea: Decapoda). Decapod crustacean phylogenetics:281-305.

Branton D, Deamer DW, Marziali A, Bayley H, Benner SA, Butler T, Di Ventra M, Garaj S, Hibbs A, Huang $X$, Jovanovich SB, Krstic PS, Lindsay S, Ling XS, Mastrangelo CH, Meller A, Oliver JS, Pershin YV, Ramsey JM, Riehn R, Soni GV, Tabard-Cossa V, Wanunu M, Wiggin M, and Schloss JA. 2008. The potential and challenges of nanopore sequencing. Nat Biotech 26:1146-1153.

Cameron SL. 2014. Insect Mitochondrial Genomics: Implications for Evolution and Phylogeny. Annual Review of Entomology 59:95-117. doi:10.1146/annurev-ento-011613-162007

Capella-Gutiérrez S, Silla-Martínez JM, and Gabaldón T. 2009. trimAl: a tool for automated alignment trimming in large-scale phylogenetic analyses. Bioinformatics 25:1972-1973. 10.1093/bioinformatics/btp348

Castellana S, Vicario S, and Saccone C. 2011. Evolutionary Patterns of the Mitochondrial Genome in Metazoa: Exploring the Role of Mutation and Selection in Mitochondrial Protein-Coding Genes. Genome Biology and Evolution 3:1067-1079. 10.1093/gbe/evr040

Castresana J. 2000. Selection of Conserved Blocks from Multiple Alignments for Their Use in Phylogenetic Analysis. Molecular biology and evolution 17:540-552.

Chong RA, and Mueller RL. 2013. Evolution Along the Mutation Gradient in the Dynamic Mitochondrial Genome of Salamanders. Genome Biology and Evolution 5:1652-1660. 10.1093/gbe/evt119

Cook CE, Yue $Q$, and Akam M. 2005. Mitochondrial genomes suggest that hexapods and crustaceans are mutually paraphyletic. Proceedings of the Royal Society of London B: Biological Sciences 272:1295-1304. 10.1098/rspb.2004.3042

Crandall KA, Harris DJ, and Fetzner JW. 2000. The monophyletic origin of freshwater crayfish estimated from nuclear and mitochondrial DNA sequences. Proceedings of the Royal Society of London B: Biological Sciences 267:1679-1686. 10.1098/rspb.2000.1195

Dowton M, and Austin AD. 1999. Evolutionary dynamics of a mitochondrial rearrangement "hot spot" in the Hymenoptera. Molecular biology and evolution 16:298-309.

Dowton M, Castro LR, and Austin AD. 2002. Mitochondrial gene rearrangements as phylogenetic characters in the invertebrates: the examination of genome 'morphology'. Invertebrate Systematics 16:345-356. http://dx.doi.org/10.1071/IS02003

Dowton M, Castro RL, Campbell LS, Bargon DS, and Austin DA. 2003. Frequent Mitochondrial Gene Rearrangements at the Hymenopteran nad3-nad5 Junction. Journal of Molecular Evolution 56:517-526. 10.1007/s00239-002-2420-3

Fahrein K, Talarico G, Braband A, and Podsiadlowski L. 2007. The complete mitochondrial genome of Pseudocellus pearsei (Chelicerata: Ricinulei) and a comparison of mitochondrial gene rearrangements in Arachnida. BMC Genomics 8:1-14. 10.1186/1471-2164-8-386

Felder DL, and Robles R. 2009. Molecular phylogeny of the family Callianassidae based on preliminary analyses of two mitochondrial genes. Decapod crustacean phylogenetics Crustacean issues 18:327-342. 
701

702

703

704

705

706

707

708

709

710

711

712

713

714

715

716

717

718

719

720

721

722

723

724

725

726

727

728

729

730

731

732

733

734

735

736

737

738

739

740

741

742

743

744

745

746

747

Gan HM, Schultz MB, and Austin CM. 2014a. Integrated shotgun sequencing and bioinformatics pipeline allows ultra-fast mitogenome recovery and confirms substantial gene rearrangements in Australian freshwater crayfishes. BMC Evol Biol 14:19. 10.1186/1471-2148-14-19

1471-2148-14-19 [pii]

Gan HY, Gan HM, Lee YP, and Austin CM. 2014b. The complete mitochondrial genome of the bass yabby Trypaea australiensis Dana 1852, (Crustacea; Decapoda; Callianassidae) - a new gene order for the Decapoda. Mitochondrial DNA:1-2. 10.3109/19401736.2014.989516

Gan HY, Gan HM, Tan MH, Lee YP, and Austin CM. 2015. The complete mitogenome of the hermit crab Clibanarius infraspinatus (Hilgendorf, 1869), (Crustacea; Decapoda; Diogenidae) - a new gene order for the Decapoda. Mitochondrial DNA:1-2. 10.3109/19401736.2014.1003862

García-Machado E, Pempera M, Dennebouy N, Oliva-Suarez M, Mounolou J-C, and Monnerot M. 1999. Mitochondrial Genes Collectively Suggest the Paraphyly of Crustacea with Respect to Insecta. Journal of Molecular Evolution 49:142-149. 10.1007/pl00006527

Gissi C, lannelli F, and Pesole G. 2004. Complete mtDNA of Ciona intestinalis Reveals Extensive Gene Rearrangement and the Presence of an atp8 and an Extra trnM Gene in Ascidians. Journal of Molecular Evolution 58:376-389. 10.1007/s00239-003-2559-6

Gissi C, lannelli F, and Pesole G. 2008. Evolution of the mitochondrial genome of Metazoa as exemplified by comparison of congeneric species. Heredity 101:301-320. http://www.nature.com/hdy/journal/v101/n4/suppinfo/hdy200862s1.html

Jia W, and Higgs PG. 2008. Codon Usage in Mitochondrial Genomes: Distinguishing Context-Dependent Mutation from Translational Selection. Molecular biology and evolution 25:339-351. 10.1093/molbev/msm259

Jiang ZJ, Castoe TA, Austin CC, Burbrink FT, Herron MD, McGuire JA, Parkinson CL, and Pollock DD. 2007. Comparative mitochondrial genomics of snakes: extraordinary substitution rate dynamics and functionality of the duplicate control region. BMC Evolutionary Biology 7:1-14. 10.1186/14712148-7-123

Katoh K, and Standley DM. 2013. MAFFT multiple sequence alignment software version 7: improvements in performance and usability. Molecular biology and evolution 30:772-780.

Kilpert F, and Podsiadlowski L. 2006. The complete mitochondrial genome of the common sea slater, Ligia oceanica (Crustacea, Isopoda) bears a novel gene order and unusual control region features. BMC Genomics 7:1-18. 10.1186/1471-2164-7-241

Kim S, Ahn D-H, Park J-K, Kim S-J, Choi H-G, and Min G-S. 2013. The complete mitochondrial genome of the Japanese ghost shrimp Nihonotrypaea japonica (Crustacea, Decapoda, Axiidea). Mitochondrial DNA 24:243-245. 10.3109/19401736.2012.752480

Kim S, Park M-H, Jung J-H, Ahn D-H, Sultana T, Kim S, Park J-K, Choi H-G, and Min G-S. 2012. The mitochondrial genomes of Cambaroides similis and Procambarus clarkii (Decapoda: Astacidea: Cambaridae): the phylogenetic implications for Reptantia. Zoologica Scripta 41:281-292. 10.1111/j.1463-6409.2012.00534.x

Li X, Huang Y, and Lei F. 2015. Comparative mitochondrial genomics and phylogenetic relationships of the Crossoptilon species (Phasianidae, Galliformes). BMC Genomics 16:1-12. 10.1186/s12864015-1234-9

Lin F-J, Liu Y, Sha Z, Tsang L, Chu K, Chan T-Y, Liu R, and Cui Z. 2012. Evolution and phylogeny of the mud shrimps (Crustacea: Decapoda) revealed from complete mitochondrial genomes. BMC Genomics 13:631.

Mao M, Gibson T, and Dowton M. 2014. Evolutionary Dynamics of the Mitochondrial Genome in the Evaniomorpha (Hymenoptera)-A Group with an Intermediate Rate of Gene Rearrangement. Genome Biology and Evolution 6:1862-1874. 10.1093/gbe/evu145 
748

749

750

751

752

753

754

755

756

757

758

759

760

761

762

763

764

765

766

767

768

769

770

771

772

773

774

775

776

777

778

779

780

781

782

783

784

785

786

787

788

789

790

791

792

793

794

795

Miller AD, Murphy NP, Burridge CP, and Austin CM. 2005. Complete Mitochondrial DNA Sequences of the Decapod Crustaceans Pseudocarcinus gigas (Menippidae) and Macrobrachium rosenbergii (Palaemonidae). Marine Biotechnology 7:339-349. 10.1007/s10126-004-4077-8

Miller AD, Nguyen TTT, Burridge CP, and Austin CM. 2004. Complete mitochondrial DNA sequence of the Australian freshwater crayfish, Cherax destructor (Crustacea: Decapoda: Parastacidae): a novel gene order revealed. Gene 331:65-72. http://dx.doi.org/10.1016/i.gene.2004.01.022

Minh BQ, Nguyen MAT, and von Haeseler A. 2013. Ultrafast Approximation for Phylogenetic Bootstrap. Molecular biology and evolution. 10.1093/molbev/mst024

Muhire BM, Varsani A, and Martin DP. 2014. SDT: A Virus Classification Tool Based on Pairwise Sequence Alignment and Identity Calculation. PLoS One 9:e108277. 10.1371/journal.pone.0108277

Nguyen L-T, Schmidt HA, von Haeseler A, and Minh BQ. 2015. IQ-TREE: A Fast and Effective Stochastic Algorithm for Estimating Maximum-Likelihood Phylogenies. Molecular biology and evolution 32:268-274. 10.1093/molbev/msu300

Oliveira DCSG, Raychoudhury R, Lavrov DV, and Werren JH. 2008. Rapidly Evolving Mitochondrial Genome and Directional Selection in Mitochondrial Genes in the Parasitic Wasp Nasonia (Hymenoptera: Pteromalidae). Molecular biology and evolution 25:2167-2180. 10.1093/molbev/msn159

Peng Y, Leung HCM, Yiu SM, and Chin FYL. 2012. IDBA-UD: a de novo assembler for single-cell and metagenomic sequencing data with highly uneven depth. Bioinformatics 28:1420-1428. 10.1093/bioinformatics/bts174

Poore GCB, Ahyong ST, Bracken-Grissom HD, Chan T-Y, Chu KH, Crandall KA, Dworschak PC, Felder DL, Feldmann RM, Hyžný M, Karasawa H, Lemaitre R, Komai T, Li X, Mantelatto FL, Martin JW, NgocHo N, Robles R, Schweitzer CE, Tamaki A, Tsang LM, and Tudge CC. 2014. On stabilising the names of the infraorders of thalassinidean shrimps, Axiidea de Saint Laurent, 1979 and Gebiidea de Saint Laurent, 1979 (Decapoda). Crustaceana 87:1258-1272. doi:http://dx.doi.org/10.1163/15685403-00003354

Poulsen JY, Byrkjedal I, Willassen E, Rees D, Takeshima H, Satoh TP, Shinohara G, Nishida M, and Miya M. 2013. Mitogenomic sequences and evidence from unique gene rearrangements corroborate evolutionary relationships of myctophiformes (Neoteleostei). BMC Evolutionary Biology 13:1-22. 10.1186/1471-2148-13-111

Prat Y, Fromer M, Linial N, and Linial M. 2009. Codon usage is associated with the evolutionary age of genes in metazoan genomes. BMC Evolutionary Biology 9:1-12. 10.1186/1471-2148-9-285

Qian G, Zhao Q, Wang AN, Zhu LIN, Zhou K, and Sun H. 2011. Two new decapod (Crustacea, Malacostraca) complete mitochondrial genomes: bearings on the phylogenetic relationships within the Decapoda. Zoological Journal of the Linnean Society 162:471-481. 10.1111/j.10963642.2010.00686.x

Rhoads A, and Au KF. 2015. PacBio Sequencing and Its Applications. Genomics, Proteomics \& Bioinformatics 13:278-289. http://dx.doi.org/10.1016/j.gpb.2015.08.002

Rice P, Longden I, and Bleasby A. 2000. EMBOSS: The European Molecular Biology Open Software Suite. Trends in Genetics 16:276-277. 10.1016/s0168-9525(00)02024-2

Robles R, Tudge CC, Dworschak PC, Poore GC, and Felder D. 2009. Molecular phylogeny of the Thalassinidea based on nuclear and mitochondrial genes. Decapod crustacean phylogenetics:309-326.

Rota-Stabelli O, Lartillot N, Philippe H, and Pisani D. 2013. Serine Codon-Usage Bias in Deep Phylogenomics: Pancrustacean Relationships as a Case Study. Systematic Biology 62:121-133. 10.1093/sysbio/sys077

Sakai K. 2011. Axioidea of the world and a reconsideration of the Callianassoidea (Decapoda, Thalassinidea, Callianassida): Brill. 
796

797

798

799

800

801

802

803

804

805

806

807

808

809

810

811

812

813

814

815

816

817

818

819

820

821

822

823

824

825

826

827

828

829

830

831
Shao R, Barker SC, Mitani H, Aoki Y, and Fukunaga M. 2005. Evolution of Duplicate Control Regions in the Mitochondrial Genomes of Metazoa: A Case Study with Australasian Ixodes Ticks. Molecular biology and evolution 22:620-629. 10.1093/molbev/msi047

Sharp PM, and Li W-H. 1987. The codon adaptation index-a measure of directional synonymous codon usage bias, and its potential applications. Nucleic Acids Research 15:1281-1295. 10.1093/nar/15.3.1281

Shen H, Braband A, and Scholtz G. 2013. Mitogenomic analysis of decapod crustacean phylogeny corroborates traditional views on their relationships. Molecular Phylogenetics and Evolution 66:776-789. http://dx.doi.org/10.1016/i.ympev.2012.11.002

Shen X, Tian M, Yan B, and Chu K. 2015. Phylomitogenomics of Malacostraca (Arthropoda: Crustacea). Acta Oceanologica Sinica 34:84-92. 10.1007/s13131-015-0583-1

Shoemaker DD, Dyer KA, Ahrens M, McAbee K, and Jaenike J. 2004. Decreased diversity but increased substitution rate in host mtDNA as a consequence of Wolbachia endosymbiont infection. Genetics 168:2049-2058.

Stokkan M, Jurado-Rivera JA, Juan C, Jaume D, and Pons J. 2016. Mitochondrial genome rearrangements at low taxonomic levels: three distinct mitogenome gene orders in the genus Pseudoniphargus (Crustacea: Amphipoda). Mitochondrial DNA Part A 27:3579-3589. 10.3109/19401736.2015.1079821

Sun Z, Wan D-G, Murphy RW, Ma L, Zhang X-S, and Huang D-W. 2009. Comparison of base composition and codon usage in insect mitochondrial genomes. Genes \& Genomics 31:65-71. $10.1007 /$ bf03191139

Tan MH, Gan HM, Schultz MB, and Austin CM. 2015. MitoPhAST, a new automated mitogenomic phylogeny tool in the post-genomic era with a case study of 89 decapod mitogenomes including eight new freshwater crayfish mitogenomes. Molecular Phylogenetics and Evolution 85:180-188. http://dx.doi.org/10.1016/j.ympev.2015.02.009

Timm L, and Bracken-Grissom HD. 2015. The forest for the trees: evaluating molecular phylogenies with an emphasis on higher-level Decapoda. JOURNAL OF CRUSTACEAN BIOLOGY 35:577-592. doi:http://dx.doi.org/10.1163/1937240X-00002371

Timmermans MJTN, Viberg C, Martin G, Hopkins K, and Vogler AP. 2016. Rapid assembly of taxonomically validated mitochondrial genomes from historical insect collections. Biological Journal of the Linnean Society 117:83-95. 10.1111/bij.12552

Whittle CA, and Extavour CG. 2015. Codon and Amino Acid Usage Are Shaped by Selection Across Divergent Model Organisms of the Pancrustacea. G3: Genes/Genomes/Genetics 5:2307-2321. 10.1534/g3.115.021402 


\section{Table 1 (on next page)}

List of source and accession number of mitogenome samples. 


\begin{tabular}{|c|c|c|c|c|c|c|}
\hline & $\begin{array}{c}\text { Callianassa } \\
\text { ceramica }\end{array}$ & $\begin{array}{l}\text { Callianassa } \\
\text { ceramica }\end{array}$ & $\begin{array}{c}\text { Trypaea } \\
\text { australiensis }\end{array}$ & $\begin{array}{l}\text { Alpheus } \\
\text { lobidens }\end{array}$ & $\begin{array}{l}\text { Caridina } \text { cf. } \\
\text { nilotica }\end{array}$ & $\begin{array}{c}\text { Macrobrachium } \\
\text { bullatum }\end{array}$ \\
\hline Family & Callianassidae & Callianassidae & Callianassidae & Alpheidae & Atyidae & Palaemonidae \\
\hline Subfamily & Callianassinae & Callianassinae & Callianassinae & $\mathrm{N} / \mathrm{A}$ & $\mathrm{N} / \mathrm{A}$ & Palaemoninae \\
\hline Location & $\begin{array}{l}\text { Anglesea, } \\
\text { South west of } \\
\text { Geelong, } \\
\text { Victoria }\end{array}$ & $\begin{array}{l}\text { South of Port } \\
\text { Authority } \\
\text { Pier, } \\
\text { Queenscliff, } \\
\text { Victoria }\end{array}$ & $\begin{array}{l}\text { Stony Point, } \\
\text { Western Port } \\
\text { Bay, Victoria }\end{array}$ & $\begin{array}{l}\text { Nightcliff, } \\
\text { Darwin, } \\
\text { Northern } \\
\text { Territory }\end{array}$ & $\begin{array}{l}\text { Amy Ward } \\
\text { Drive, } \\
\text { Darwin, } \\
\text { Northern } \\
\text { Territory }\end{array}$ & $\begin{array}{c}\text { Rapid Creek, } \\
\text { Darwin, } \\
\text { Northern } \\
\text { Territory }\end{array}$ \\
\hline Voucher & N/A & $\begin{array}{l}\text { NMV } \\
\text { J40715 }\end{array}$ & $\begin{array}{l}\text { NMV } \\
\text { J40711 }\end{array}$ & $\begin{array}{l}\text { MAGNT } \\
\text { Cr.18581 }\end{array}$ & N/A & N/A \\
\hline Verification & $\begin{array}{c}99.8 \% \\
(660 \text { bp COI })^{1}\end{array}$ & N/A & N/A & N/A & $\begin{array}{c}100 \% \\
(326 \mathrm{bp} \mathrm{16S})^{2}\end{array}$ & $\begin{array}{c}100 \% \\
(447 \mathrm{bp} 16 \mathrm{~S})^{3}\end{array}$ \\
\hline Accession \# & KU362925.1 & KU350630.1 & KM501040.2 & KP276147.1 & KU726823.1 & KM978918.1 \\
\hline
\end{tabular}




\section{Table 2(on next page)}

List of samples and their corresponding accession numbers included in phylogenetic and comparative analyses. 


\begin{tabular}{|c|c|c|c|c|}
\hline Infraorder & Family & Species & Accession & Reference \\
\hline \multirow[t]{8}{*}{ Axiidea } & \multirow[t]{7}{*}{ Callianassidae } & Callianassa ceramica & KU350630.1 & This study \\
\hline & & Callianassa ceramica & KU362925.1 & Gan et al. (2014b) \\
\hline & & Corallianassa coutierei & NC_020025.1 & Shen et al. (2013) \\
\hline & & Nihonotrypaea japonica & $\mathrm{NC}_{-}^{-} 020351.1$ & Kim et al. (2013) \\
\hline & & Nihonotrypaea thermophile & NC_019610.1 & Lin et al. (2012) \\
\hline & & Paraglypturus tonganus $^{1}$ & NC_024651.1 & Kim et al. (2016b) \\
\hline & & Trypaea australiensis ${ }^{2}$ & KMㄷ01040.2 & This study \\
\hline & Strahlaxiidae & Neaxius glyptocercus & NC_019609.1 & Lin et al. (2012) \\
\hline \multirow[t]{5}{*}{ Gebiidea } & Thalassinidae & Thalassina kelanang & NC_ 019608.1 & Lin et al. (2012) \\
\hline & \multirow[t]{4}{*}{ Upogebiidae } & Austinogebia edulis & $\mathrm{NC}_{-}^{-} 019606.1$ & Lin et al. (2012) \\
\hline & & Upogebia major & $\mathrm{NC}^{-} 019607.1$ & Lin et al. (2012) \\
\hline & & Upogebia pusilla & NC_-020023.1 & Shen et al. (2013) \\
\hline & & Upogebia yokoyai & NC_025943.1 & Yang et al. (2016) \\
\hline \multirow[t]{20}{*}{ Caridea } & \multirow[t]{6}{*}{ Alvinocarididae } & Alvinocaris chelys & NC_018778.1 & Yang et al. (2012) \\
\hline & & Alvinocaris longirostris & $\mathrm{NC}_{-}^{-} 020313.1$ & Yang et al. (2013) \\
\hline & & Nautilocaris saintlaurentae & NC_021971.1 & Kim et al. (2015a) \\
\hline & & Opaepele loihi & NC_020311.1 & Yang et al. (2013) \\
\hline & & Rimicaris exoculata & $\mathrm{NC}_{-}^{-} 027116.1$ & Yu et al. (2015) \\
\hline & & Rimicaris kairei & NC_020310.1 & Yang et al. (2013) \\
\hline & \multirow[t]{2}{*}{ Alpheidae } & Alpheus distinguendus & NC_014883.1 & Qian et al. (2011) \\
\hline & & Alpheus lobidens & KP $\overline{2} 76147.1$ & This study \\
\hline & \multirow[t]{5}{*}{ Atyidae } & Caridina gracilipes & NC_024751.1 & $\mathrm{Xu}$ et al. (2016) \\
\hline & & Caridina cf. nilotica & KU7̄26823.1 & This study \\
\hline & & Halocaridina rubra & NC_008413.1 & Ivey \& Santos (2007) \\
\hline & & Neocaridina denticulata & NC_023823.1 & Yu et al. (2014) \\
\hline & & Paratya australiensis & NC_027603.1 & Gan et al. (2015a) \\
\hline & \multirow[t]{7}{*}{ Palaemonidae } & Macrobrachium bullatum & KMำ78918.1 & This study \\
\hline & & Macrobrachium lanchesteri & NC_012217.1 & Unpublished \\
\hline & & Macrobrachium nipponense & NC_015073.1 & Ma et al. (2011) \\
\hline & & Macrobrachium rosenbergii & NC_006880.1 & Miller et al. (2005) \\
\hline & & Palaemon carinicauda & $\mathrm{NC}_{-}^{-} 012566.1$ & Shen et al. (2009) \\
\hline & & Palaemon gravieri & NC_029240.1 & Kim et al. (2015b) \\
\hline & & Palaemon serenus & NC_-027601.1 & Gan et al. (2015b) \\
\hline \multirow{12}{*}{$\begin{array}{l}\text { Dendrobranchiata } \\
\text { (outgroup) }\end{array}$} & Sergestidae & Acetes chinensis & NC_017600.1 & Kim et al. (2012a) \\
\hline & \multirow{10}{*}{ Penaeidae } & Farfantepenaeus californiensis & NC_012738.1 & Gutiérrez-Millán et al. (2002) \\
\hline & & Fenneropenaeus chinensis & NC_009679.1 & Shen et al. (2007) \\
\hline & & Fenneropenaeus merguiensis & NC_026884.1 & Zhang et al. (2016a) \\
\hline & & Fenneropenaeus penicillatus & $\mathrm{NC}_{-}^{-} 026885.1$ & Zhang et al. (2015) \\
\hline & & Litopenaeus vannamei & NC_009626.1 & Unpublished \\
\hline & & Marsupenaeus japonicas & NC_007010.1 & Yamauchi et al. (2004) \\
\hline & & Metapenaeopsis dalei & NC_029457.1 & Kim et al. (2016a) \\
\hline & & Metapenaeus ensis & $\mathrm{NC}_{-}^{-} 026834.1$ & Zhang et al. (2016b) \\
\hline & & Parapenaeopsis hardwickii & NC_030277.1 & Mao et al. (2016) \\
\hline & & Penaeus monodon & NC_002184.1 & Wilson et al. (2000) \\
\hline & Solenoceridae & Solenocera crassicornis & $\mathrm{NC}-030280.1$ & Unpublished \\
\hline
\end{tabular}

1

$2 \quad{ }^{1}$ Paraglypturus tonganus (nomen nudum)

32 Mitogenome from taxonomically verified $T$. australiensis sample resubmitted as version two under same accession 4 number 


\section{Table 3(on next page)}

List of samples for which annotations were corrected based on re-annotation with MITOS. 


\begin{tabular}{clcl}
\hline Accession \# & \multicolumn{1}{c}{ Species } & $\begin{array}{c}\text { Genes } \\
\text { involved } \dagger\end{array}$ & Correction/Edits made in this study \\
\hline NC_024751.1 & Caridina gracilipes & ND2, trnS & Added ND2, removed duplicated trnS \\
NC_012217.1 & Macrobrachium lanchesteri & rrnS, rrnL & Inverted coordinates for rrnS and rrnL \\
NC_020025.1 & Corallianassa coutierei & trnI, trnQ & Inverted coordinates for trnI and trnQ \\
NC_020351.1 & Nihonotrypaea japonica & rrnS, rrnL & Added rrnS and rrnL coordinates \\
\hline
\end{tabular}

1

$2 \uparrow$ Genes involved in discrepancies found between NCBI's RefSeq entry and re-annotation with MITOS 
Figure 1

Circular representation of three caridean and two axiidean species

These figures show composition and order of protein-coding genes (blue), ribosomal RNAs (orange), transfer RNAs (purple) and large non-coding region (grey) for the following mitogenomes: A. Alpheus lobidens, B. Caridina cf. nilotica, C. Macrobrachium bullatum, D. Callianassa ceramica, E. Trypaea australiensis.
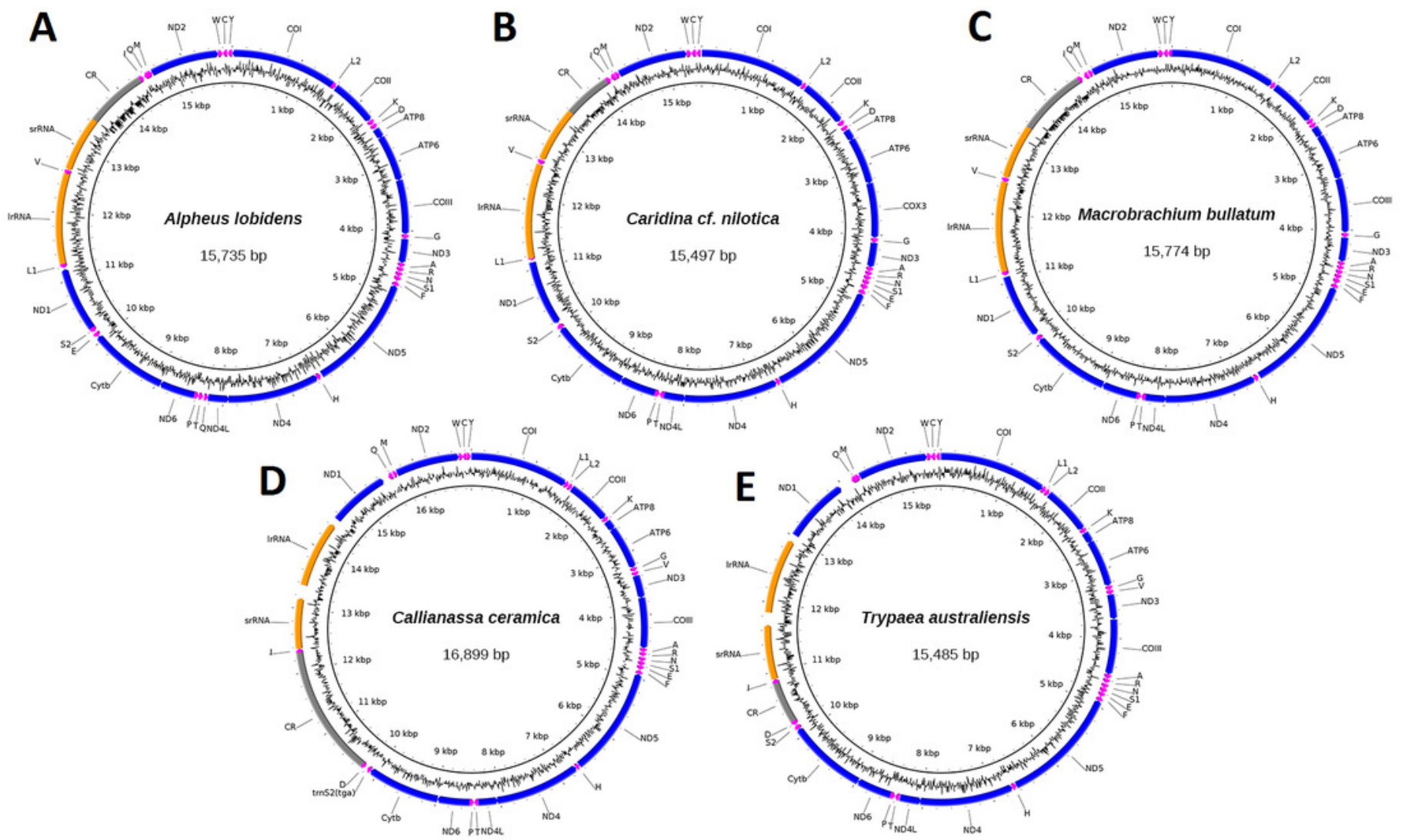


\section{Figure 2}

Phylogenetic relationships and gene order rearrangements within Axiidea, Gebiidea and Caridea.

A. Phylogenetic tree with support values indicated at each node (top, I-r: ML and BI support for PCG (aa) + 12S + 16S dataset), bottom, I-r: ML and BI support for PCG (nt) + 12S + 16S dataset). Square brackets [ ] around a value indicate that the shown topology is in conflict with that constructed by the specific dataset. If values are absent at a node, maximum support was found for that node based on all phylogenetic inference methods and datasets. Topology shown was inferred from Bayesian analysis of PCG (aa) $+12 S+165$ dataset. Codes on branches (Gr, Pa, Ap1, Ap2, Up, Ax1, Ax2) correspond to gene order pattern listed in $\mathrm{B}$ while red stars indicate mitogenomes sequenced in this study. - B. Gene order of various groups. Yellow triangles under genes indicate differences in arrangement compared to the ground pancrustacean pattern. 


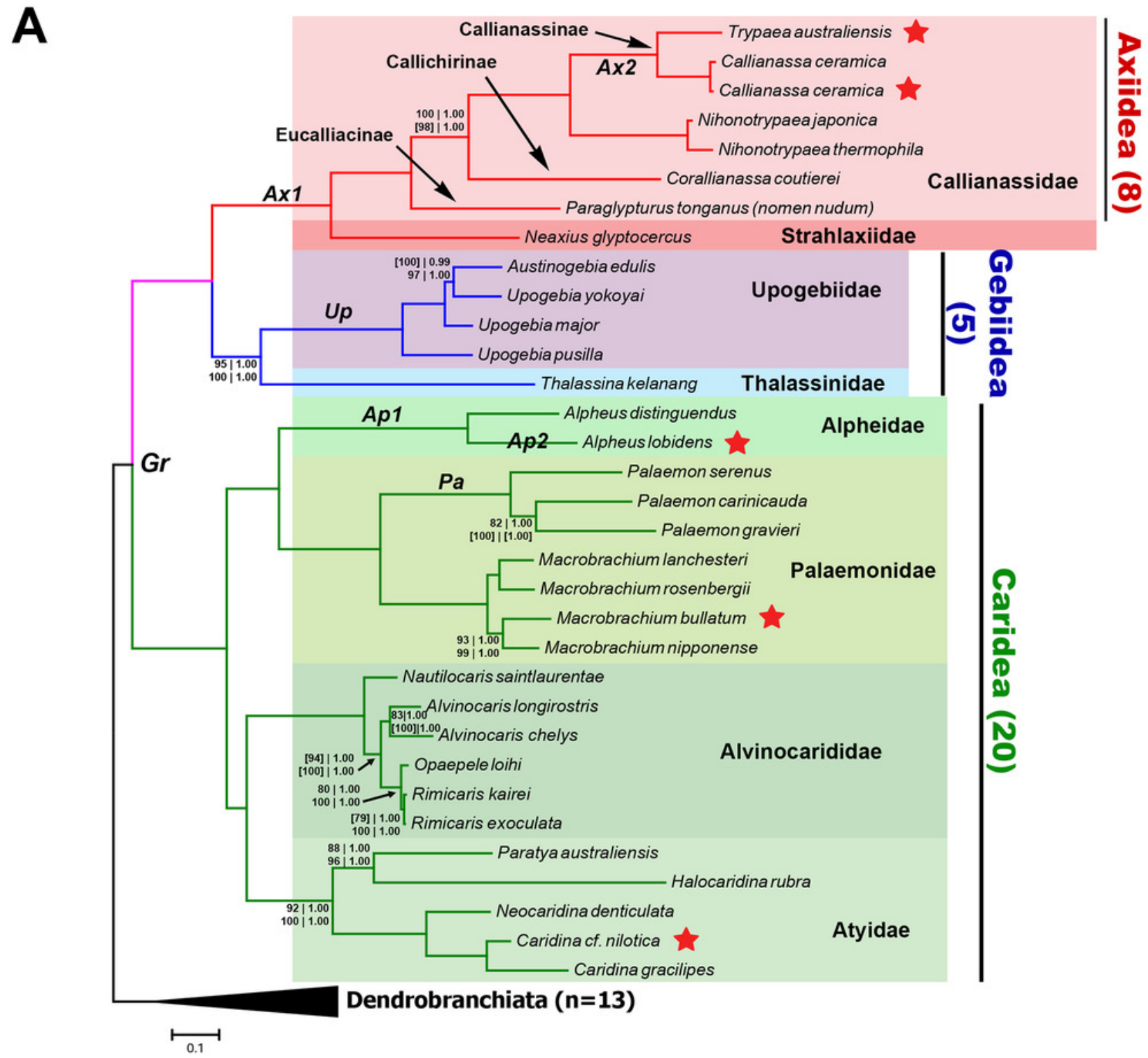

B

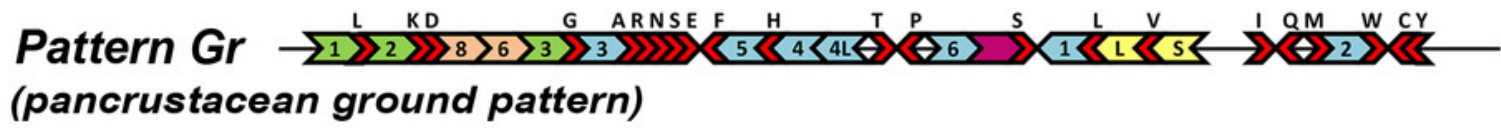

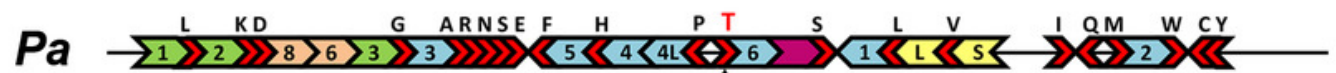

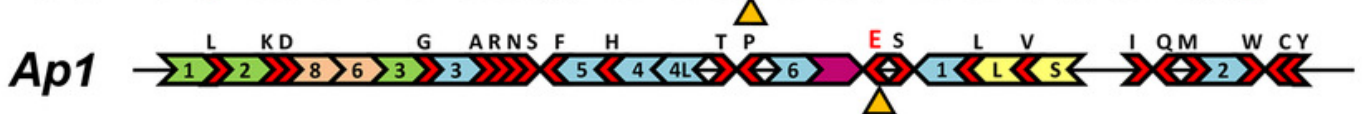

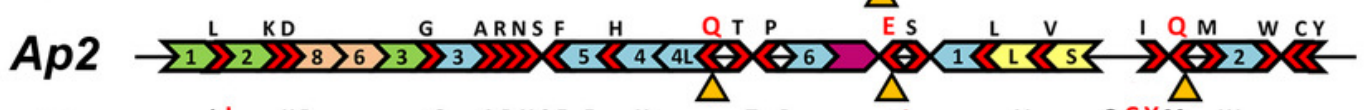

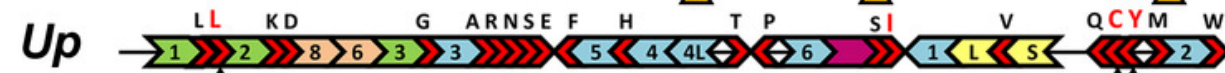
$\sum_{\substack{\text { ATP } \\ \text { rRNA }}}^{\sum_{\text {tRNA }}^{\text {CO }}}$

$\triangle$ Difference relative to pattern $\mathrm{Gr}$

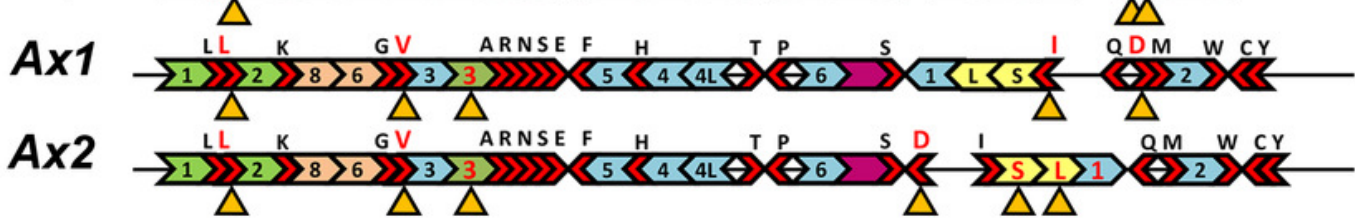


Figure 3

Relative synonymous codon usage values (RSCU) (y-axis) in protein-coding genes of mud shrimps and true shrimps

Encoded amino acid and its corresponding p-value ( $>$ or $<0.001$ ) is shown at the top of each box plot while synonymous codons are indicated on the $x$-axis.

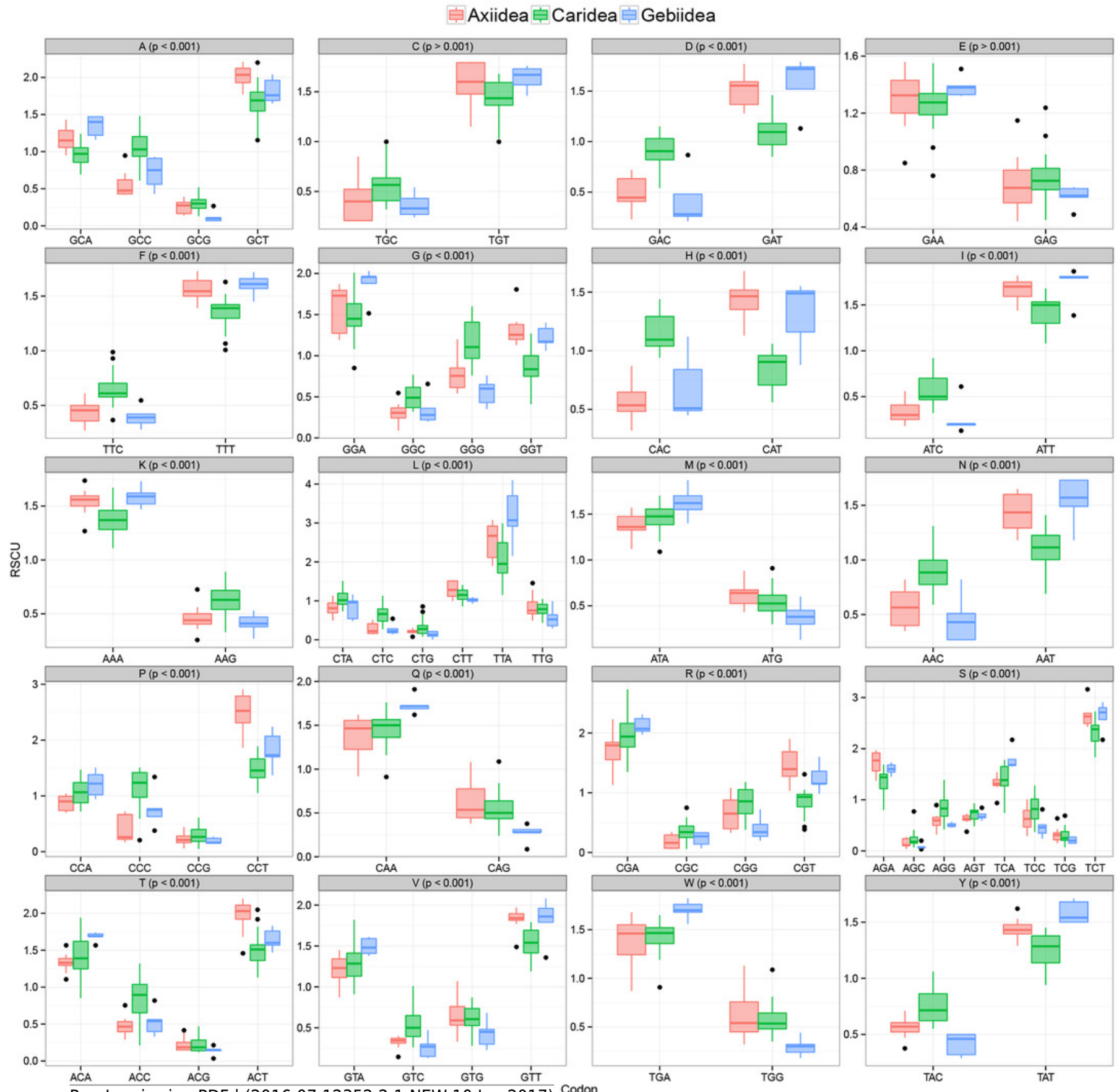


Figure 4

Patterns of variation among individuals based on RSCU values shown using multidimensional scaling (MDS) based on Euclidean dissimilarities.

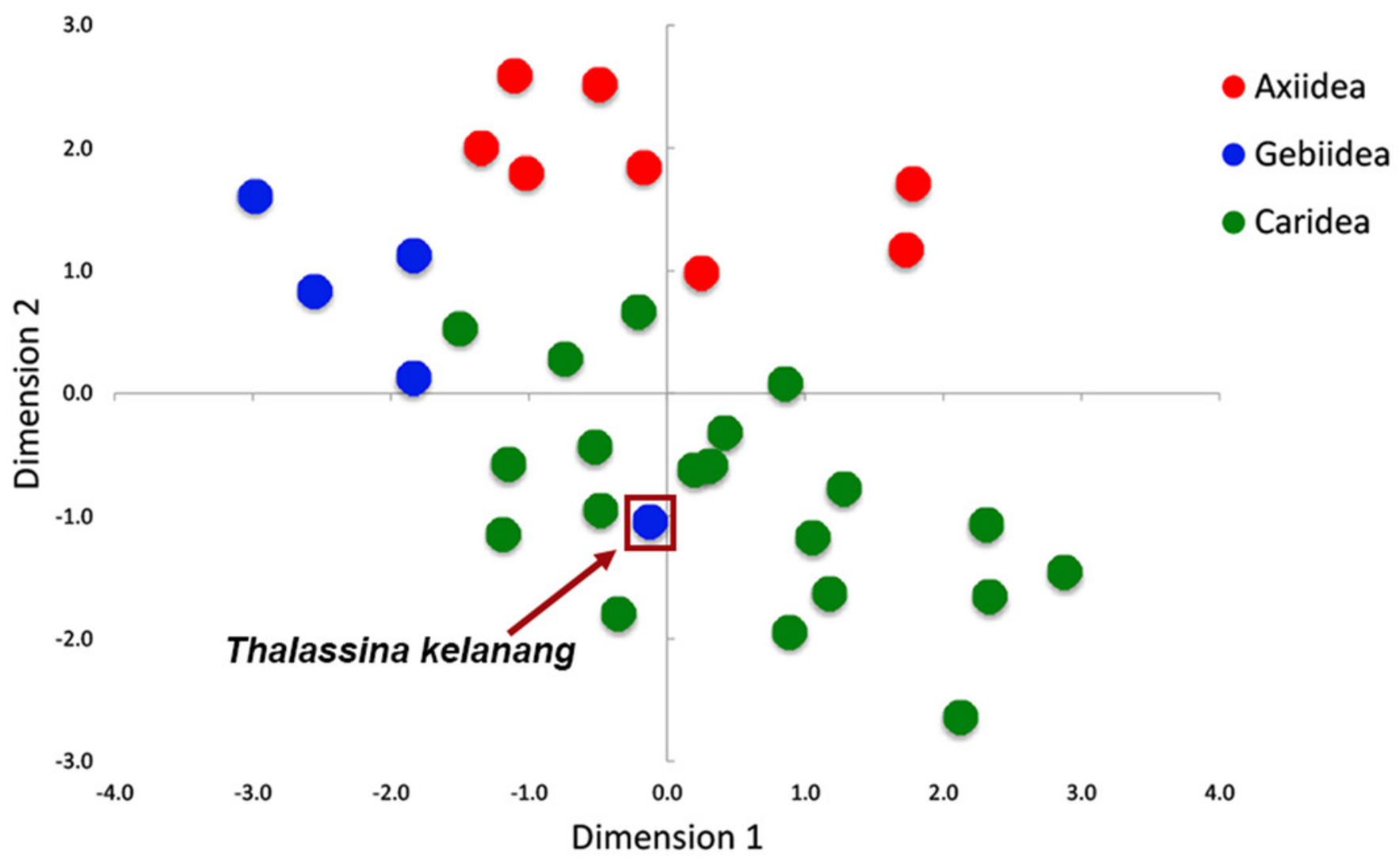

